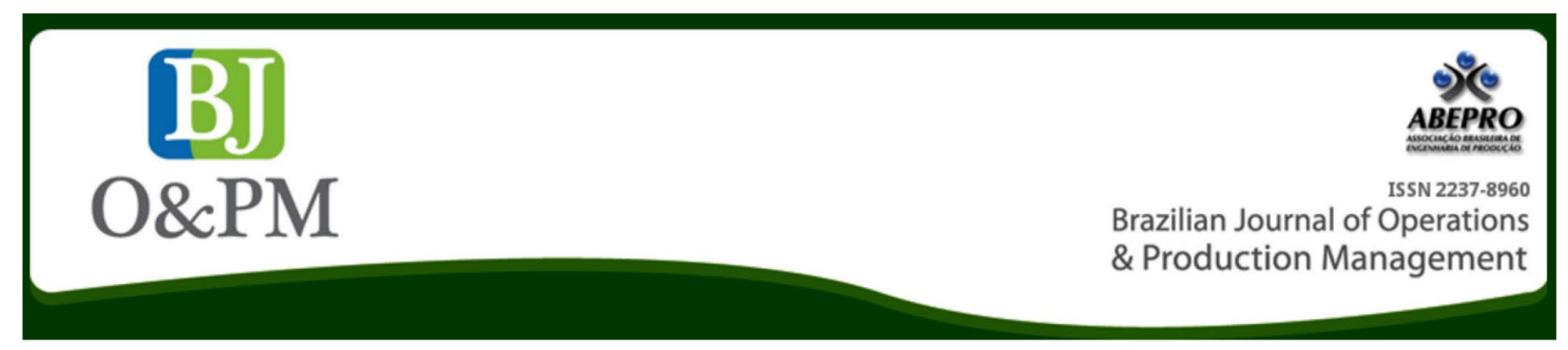

\title{
APPLICATION OF THE SUSTAINABLE LOGISTICS PLAN IN THE PUBLIC ADMINISTRATION
}

\section{Andréa Cristiane Sales} Moreira

andreasalesmor@gmail.com Fluminense Federal University, Niterói, Rio de Janeiro, Brazil.

\begin{abstract}
The Public Administration, when it consumes the natural resources in a conscious way, contributes to diminishing the negative repercussions of its activities on the environment. It is important to highlight the relevance of sustainable decisions of public managers, contributing to the achievement of positive results for the planet and the quality of life of people in the next fifteen years, supported by Agenda 2030. It is the primary objective of this study, of the constitutional principle of sustainable development - foreseen in Article 225, Brazilian Federal Constitution - and how it has been applied in the socio-environmental management of the Judicial Branch of the State of Rio de Janeiro, consistent with the assumptions of Agenda 2030, evaluating the main initiatives underway regarding the incorporation of the Goals of Sustainable Development (SDG). To this end, the stages of implementation of the Sustainable Logistics Plan (PLS) of the Rio de Janeiro State Court of Justice (TJERJ) are presented, based on exploratory and documentary research, in search for theoretical and legal support. The importance of establishing monitoring and evaluation processes was also verified, guiding the public manager in the construction of a new institutional culture in public bodies.
\end{abstract}

Keywords: Sustainable Development Goals; Agenda 2030; Social and environmental management Public Administration; Judicial Branch of the State of Rio de Janeiro. 
Brazilian Journal of Operations \& Production Management

Volume 15, Número 1, 2018, pp. 137-142

DOI: 10.14488/BJOPM.2018.v15.n1.a12

\section{INTRODUCTION}

The development of social and environmental actions in the Brazilian public administration is a fundamental process in the socioeconomic conjuncture. Understanding how the public entities of the country act, how they invest their resources, how they use their infrastructures (water, energy, waste), how they produce goods and services and how they consume and dispose of their waste are issues that stimulate changes in the economic, social and political system.

Based on the aforementioned context and aiming at guiding public administration managers, the objective of this research is to seek a better understanding of the Sustainable Development Goals (SDG) and to analyze their compliance in the social and environmental management of the Court of Justice of the State of Rio de Janeiro, identifying the main initiatives developed and their actual contribution. For this purpose, the process of implementation of the Sustainable Logistics Plan of the Court of Justice of the State of Rio de Janeiro was used as a guide.

\section{LITERATURE REVIEW}

This section addresses concepts related to the topic of study; among them, Environmental Management in Public Administration and Sustainable Development Goals (SDG).

\section{Sustainability in Public Administration}

The challenges for the implementation of a sustainable management policy in public institutions are numerous, requiring varied expertise. Based on these premises, we can say that, in Brazil, several programs, policies and tools for the application of sustainability in the various spheres of government and of the three powers have been established, such as the Environmental Agenda in Public Administration (A3P) and the Sustainable Logistics Plan (PLS).

The Environmental Agenda in Public Administration (A3P) is a voluntary initiative of the Ministry of the Environment (MMA) and its goal is to promote the internalization of the social and environmental principles regarding sustainability in public bodies and entities, the three branches of government (Executive, Legislative and Judiciary) and the country's jurisdictions (municipal, state and federal) (Ferreira, 2012).

The Sustainable Logistics Plan (PLS) is considered a planning tool with defined objectives and responsibilities, actions, goals, execution deadlines that allow the organization to establish sustainability practices focused on rationalizing expenditures and combating waste in Public Administration (Scartezini et al., 2015).
Within the scope of the Judiciary Branch, the Sustainable Logistics Plan became mandatory with the publication by the National Justice Council (CNJ) of Resolution No. 201, of March 3, 2015, which disciplined the creation and competence of environmental units in the organs and councils of such branch and the implementation of the respective Sustainable Logistics Plan (Conselho Nacional de Justiça do Brasil, 2015).

The elaboration of the PLS came with Normative Instruction 10, of November 12, 2012, of the Ministry of Planning, Budget and Management (MPOG), in compliance with the provisions of Decree No. 7,746/2012. The decree regulated the amendment of article 3 of Law No. 8.666/93 (Law on Bids) regarding the establishment of criteria, practices and guidelines for the promotion of national sustainable development through the contracting and acquisitions made by the federal public administration. This initiative was born from the need to create a unified policy at the federal level, for the rational and sustainable use of natural resources in public facilities (Brasil, 2014).

\section{Agenda}

The historical evolution of the Sustainable Development Goals (SDGs) began in 2000, when the UN and its Member States established a global pact, called the Millennium Development Goals (MDGs). Focused on developing nations, the pact was consolidated through the Millennium Declaration, and proposed targets to be met by 2015. The eight Millennium Development Goals (MDGs) proposed were to: Reduce Poverty; Achieve universal primary education; Gender equality and women's empowerment; Reduce child mortality; Improve maternal health; Combat HIV/AIDS, malaria and other diseases; Ensure environmental sustainability; and Establish a global partnership for development (United $\mathrm{Na}$ tions Development Program, 2016).

By the end of 2015, joint efforts to reach the MDGs have not ended. In September 2015, a meeting of the United Nations heads of State on Sustainable Development approved the new sustainable development agenda, entitled "Transforming Our World: The 2030 Agenda for Sustainable Development", officially in force as of January 1, 2016 and implementation by 2030, thus establishing the 17 Sustainable Development Goals (SDGs), which will guide global actions for another 15 years. The new development agenda includes commitments that apply to both developing and developed countries (United Nations Development Program, 2016).

The set of 17 goals, with 169 associated goals, demonstrates the scale and ambition of this new international commitment. The approved SDGs were built on the foundations set by the Millennium Development Goals (MDGs) in 
order to answer to new challenges. They are integrated and indivisible, and blend, in a balanced way, the three dimensions of sustainable development: economic, social and environmental. The proposed Sustainable Development Goals (SDGs) are (United Nations Development Program, 2016):

1. End poverty in all its forms, everywhere.

2. End hunger, achieve food security, improve nutrition and promote sustainable agriculture.

3. Ensure healthy life and promote well-being for all, at all ages.

4. Ensure inclusive and equitable quality education and promote lifelong learning opportunities for all.

5. Achieve gender equality empower all women and girls.

6. Ensure availability and sustainable management of water and sanitation for all.

7. Ensure access to cheap, reliable, sustainable and modern energy for all.

8. Promote sustained, inclusive and sustainable economic growth, full and productive employment, and decent work for all.

9. Build resilient infrastructure, promote inclusive and sustainable industrialization, and foster innovation.

10. Reduce inequality within and among countries.

11. Make cities and human settlements inclusive, secure, resilient and sustainable.

12. Ensure sustainable consumption and production patterns.

13. Take urgent action to combat climate change and its impacts.

14 -Conserve and promote the sustainable use of oceans, seas and marine resources for sustainable development.

15. Protect, recover and promote the sustainable use of terrestrial ecosystems, sustainably manage forests, combat desertification, and halt and reverse land degradation and biodiversity loss.

16. Promote peaceful and inclusive societies for sustainable development, provide access to justice for all, and build effective, accountable and inclusive institutions at all levels.

17. Strengthen the means of implementation and revitalize the global partnership for sustainable development.

The Social and Environmental Management, implemented in the Court of Justice of the State of Rio de Janeiro, was established in order to better understand SDG and to meet the respective goals set forth in the 2013 Agenda.

\section{RESEARCH METHOD}

In this study, exploratory and documentary research was adopted as a methodological approach, seeking theoretical and legal bases for a better understanding of socio-environmental management in the Public Administration and the Sustainable Development Goals (SDGs), highlighting the case study of sustainable initiatives in TJERJ and, consequently, its contribution to the achievement of the respective SDGs.

\section{SUSTAINABLE MANAGEMENT OF THE COURT OF JUSTICE OF THE STATE OF RIO DE JANEIRO}

\section{Steps for Implementation of the Sustainable Logistics Plan (PLS) in the TJERJ}

The Court of Justice of the State of Rio de Janeiro understands that it is the responsibility of the public entities to contribute to the change of organizational culture, giving an example in the patterns of production and consumption and the preservation of natural resources, reducing the environmental impacts of its activities, encouraging the implementation of programs and practices for reusing and recycling materials and fighting against waste.

According to Pereira Junior (2015), the current size of the organizational structure of the TJERJ comprises 797 jurisdictional bodies (those that provide first and second instances) and 700 administrative units (those that take care of logistical and financial support activities in general), distributed in the 81 Counties of the State, $694,816.59 \mathrm{~m}^{2}$, occupying 154 properties, where about 859 magistrates, 16,000 servers, 5,000 outsourced service providers, 4,123 interns, and a floating public members of the Public Prosecutor's Office, lawyers, prosecutors, public defenders and other actors in judicial proceedings, such as parties, witnesses, experts, among other groups that are part of the daily routine of justice. As for its proceedings, it has a volume of more than two million new lawsuits distributed, alongside the amount of those that were judged each year, reproducing a collection 
of around nine million, as depicted in TJERJ's monthly electronic newsletter in numbers for March 2016.

With the size of its structure, as well as the need to promote a change in its organizational culture, it became essential for TJERJ to carry out a socio-environmental planning, seeking guidance in structured governmental programs. For this reason, in 2010, on the initiative of the Department of Pro-Sustainability Actions, TJERJ signed the agreement with the Ministry of the Environment, adhering to the Environmental Public Administration Agenda (A3P), becoming the second State Court to be part of the A3P Network. By agreeing to the said program, it established new administrative guidelines, with the purpose of constructing a socioenvironmental culture in its units. In 2013, this commitment was renewed, for a period of another 5 years (Pereira Junior, 2015).

The National Justice Council (Conselho Nacional de Justiça - CNJ, in Portuguese), on March 3, 2015, through the issuance of Resolution No. 201, specified to all organs of the Judiciary Branch regarding the obligation to create socio-environmental units, as well as the elaboration and implementation of PLS-PJ (Sustainable Logistics Plan - Judiciary Branch) (Conselho Nacional de Justiça do Brasil, 2015).

Since 2010, the Judiciary Branch has complied with the provisions of Articles 1 and 12 of the aforementioned Resolution, regarding the creation of a Commission and a Social and Environmental Unit, which have been part of the TJERJ structure since Executive Act No. 108 of 2015 and Resolution TJ/OE/RJ No. 17/2014, which instituted the Commission for Institutional Policies for the Promotion of Sustainability (COSUS), the Department of Actions for Sustainability (DEAPE) and the Environmental Management Division (DIGAM), also following the orientation of Article 7, since these units are subordinated to the Presidency of the TJERJ (Rio de Janeiro, Judiciary Branch, 2015).

In compliance with Article 10 of Resolution No. 201/2015, the TJERJ PLS is composed of defined objectives and responsibilities, actions, goals, and execution deadlines that allow establishing and monitoring sustainability practices (Rio de Janeiro, Judiciary Branch, 2015).

The preparation of the PLS-TJERJ was completed and approved by the Presidency of the Judiciary Branch of State of Rio de Janeiro in August 2015, and the 180-day deadline stipulated in the aforementioned Resolution in its Article 21, and its implementation started soon after approval (Rio de Janeiro, Judiciary Branch, 2015).

The Court of Justice of the State of Rio de Janeiro established a methodology for the elaboration of the aforementioned plan. The work methodology was proposed by DEAPE/DIGAM and approved by COSUS at a meeting held on
May 7, 2015, where CNJ's Resolution No. 201/2015 was analyzed, highlighting the need for elaboration of the Sustainable Logistics Plan for the Judiciary Branch (Rio de Janeiro, Judiciary Branch, 2015).

Briefly, the methodology established for the elaboration of the PLJ of the TJERJ was composed of the following six steps (Rio de Janeiro, Judiciary Branch, 2015):

- Step 1 - Diagnosis: TJERJ performed its own and specific diagnoses for its realities. The elaboration of the diagnosis was focused on the survey of sustainability practices and rationalization of the use of materials and services. In this process, the actions in progress and the opportunities for improvement were raised.

- Step 2 - Preparation of the Plan: proposals were suggested for initiatives and actions to be included in the plan. The responsible personnel, deadlines and possible involved in the implementation of actions were also identified. The proposals were discussed and approved by COSUS and became part of the PLS.

- Step 3 - Approval of the Plan: The PLS proposal was submitted for evaluation and approval by the Presidency of the Court of Justice of the State of Rio de Janeiro.

- Step 4 - Implementation of the Plan.

- Step 5 - Monitoring of the Plan by DEAPE/DIGAM.

- Step 6 - Evaluation and Critical review with revision of the goals.

Thus, on Sept. 05, 2015, TJERJ complied with the provisions of Article 21, which determines the deadline of 180 days, publication of the PLS in its respective site, summing up 56 (fifty-six) proposed initiatives, deployed in 215 (two hundred and fifteen) actions and measures by 81 (eightyone) indicators, to be implemented in the period from 2015 to 2020 (Rio de Janeiro, Judiciary Branch, 2015).

TJERJ attributes to its socio-environmental unit the responsibility for the general monitoring of the PLS indicators, by analyzing the monthly reports sent by the respective General Boards of Directors responsible for the proposed initiatives. These reports contain the consolidation of the achieved results, the evolution of the indicators' performance in the ongoing month. DEAPE/DIGAM provides COSUS with the information regarding the performance of the indicators, aiming at the elaboration and referral to the CNJ, at the end of each year, of the Performance Report of the PLS-PJ, in compliance with Article 23 of Resolution No. 201 (Conselho Nacional de Justiça do Brasil, 2015). The coordi- 
nators of the Thematic Committees (TCS) are responsible for consolidating and forwarding their Action Plans to DEAPE/ DIGAM. The PLS representatives of the General Boards of Directors follow the indicators and goals, contributing to the implementation of the initiatives proposed in the thematic axes of the TJERJ PLS.

\section{Sustainable Partnerships and Events promoted by the Court of Justice of the State of Rio de Janeiro}

Several partnerships have been established and trained employees have been driving the execution of agreements that support the various initiatives foreseen in the thematic axes (Pereira Junior, 2015).

The main partnerships and events established by the TJERJ were:

- Ministry of the Environment - Formation of the Rio Sustainability Network with the participation of representatives of federal, state and municipal administration bodies based in Rio de Janeiro, with the purpose of sharing experiences and support (Rio de Janeiro, Judiciary Branch, 2015).

- The Botanical Garden Research Institute, the State Court of Accounts (TCE) and the State Public Ministry (MP) and the Rio de Janeiro State Court of Justice (TJERJ) signed a Protocol of Intent on April 12, 2017 to establish the Rio Sustainability Network. The goal is to implement actions that promote the development of sustainable practices of governmental bodies and public entities. It is a work of exchange of sustainability practices (Rio de Janeiro, Judicial Branch, 2016).

- The Pontifical Catholic University of Rio de Janeiro (PUC/RIO), the Botanical Garden Research Institute, the Brazilian Human Resources Association (ABRH) and the Court of Justice of the State of Rio celebrated four months of (PLS-PJ) on November 30, 2015. The ceremony was attended by PUC/RIO, the Botanical Garden Research Institute and ABRH. The event coincided with the opening of the Climate Conference in Paris (COP 21) in the French capital. The event was also marked by a lecture by the rector of PUC/Rio, professor and priest Josafá Carlos de Siqueira, "The great global challenges of Pope Francisco, Francisco's Ecological Encyclical -Laudado Si" (in the Portuguese language, Louvado Sejas), which brings an appeal so that we can unite before this great environmental challenge, to safeguard, save and preserve the patrimony that God has made available to all (Rio de Janeiro, 2015).
- State Secretariat of Environment - Partnership aimed at promoting institutional integration in the execution of cooperation and technical assistance activities in environmental management.

- Fluminense Federal University (UFF), through the LATEC Institute - Protocol of intentions of technical cooperation with the purpose of offering a program of continuing education, as well as cooperation and technical advice.

- $\quad$ AMPLA - A partnership that sought to implement measures to reduce electricity consumption (Rio de Janeiro, Judiciary Branch, 2011).

- $\quad$ Rio de Janeiro State University (UERJ) - Agreement that had the scope of support for the elaboration of the Solid Waste Management Plan (Rio de Janeiro, Judicial Branch, 2015).

- $\quad$ ELETROBRAS - A protocol of intentions regarding technical cooperation for the development of integrated actions related to aid in the PROCEL EDIFICA-INMETRO labeling process was signed, contributing to the building of the Niterói Forum, receiving the $B$ classification, a series of four levels. According to the representative of the Department of Energy Efficiency Projects of Eletrobras, the importance of this seal is that the Brazilian buildings, for the most part, are at level $D$ in terms of energy efficiency. The difference from level $B$ to $D$ is about $30 \%$ in saving public spending on energy. The seal is granted by Eletrobras to buildings that have a structure with energy efficiency. The three main points taken into account for the concession of the seal in the public buildings are envelopment, lighting and air conditioning. The systems evaluated by the project at the Niterói Forum were the reuse of water, the use of taps that save water, the central air conditioning system and lighting (Rio de Janeiro, Judiciary Branch, 2014).

- $\quad$ Rio de Janeiro State Planning and Management Secretariat (SEPLAG) - In order to facilitate access to the Expenditure Management System of the State Government of Rio de Janeiro (Rio de Janeiro, 2013).

\section{CONCLUSION}

It is clear that there are innumerable administrative guidelines designed to build a new institutional culture in public bodies and entities. The requirement of sustainable governance of government entities is nothing more than the need for public administration to serve as a model for compliance with the various social and environmental stan- 
dards of the Brazilian legal system, as well as formulate perspectives. Since 1988, the Federal Constitution ensures, in its Article 225, the principle of sustainable development for present and future generations.

Facing this imperative scenario, it is the responsibility of public organizations to promote innovation regarding strategies and procedures that undoubtedly include the Sustainable Development Goals linked to the fulfillment of Agenda 2030.

The Rio de Janeiro State Court of Justice (TJERJ), through its socio-environmental management, has incorporated into its sustainable initiatives, classified under thematic axes, several of these Sustainable Development Goals, such as: (I) Rational Use of Natural Resources - incorporating SDGs 6 and 7, which address water and energy issues; (II) Management of - SDG 8 - which provides decent work for all; (III) Quality of life - SDG 3 - whose scope is to promote well-being and a healthy life; (IV) Environmental Education - SDG 4 - which "aims to guarantee inclusive and quality education; (V) Sustainable Bidding - SDG 12 - which aims to ensure sustainable consumption and production patterns; (VI) Sustainable Constructions - which aims at constructing and promoting innovation; (VII) Social Responsibility - SDG 1 - that aims at ending poverty and SDG 2, with hunger and promoting sustainable agriculture; VIII) Partnerships - SDG 17 - that stimulate the global partnership for sustainable development; IX) Social and Environmental Management of the TJERJ $16^{\text {th }}$ SDG, known as the goal of good governance and, finally, $\mathrm{X}$ ) Partnerships contribute to SDG 17 - implementing the global partnership for sustainable development.

The importance of establishing a tool for monitoring and evaluating the impacts of public policy adopted was verified, since it improves the orientation and qualification of institutional decision-making processes. Sustainability imposes on managers the recurrent visualization of long-term public policies.

\section{REFERENCES}

Brasil (2014), Ministério do Planejamento, Orçamento e Gestão, Secretaria de Planejamento e Investimento Estratégico. Planos de gestão de logística sustentável: contratações públicas sustentáveis, Ministério do Planejamento, Orçamento e Gestão, Brasília, DF.

Conselho Nacional de Justiça do Brasil (2015), Resolução No. 201, de 3 de março de 2015, available from: http:// www.cnj.jus.br///images/atos_normativos/resolucao/resolucao_201_03032015_09032015165941.pdf (Access: 20 Jun 2016).

Pereira Junior, J. T. (2015a), "Sustainability and planning: constitutional values governing administrative contracting, in the democratic state of law", in: Quelhas, O. et al. (Orgs.), Organizational transformation for sustainability: developing a Social Responsibility Management System, B. Biz, Rio de Janeiro, pp. 162-88.

Pereira Junior, J. T. (2015b), "Sustainability and Planning: Constitutional Values Rectors of Administrative Contracting in the Democratic State of Law", Public Interest, Vol. 91, pp. 27-52.

Scarterzini, K. F. A. L. et al. (2015), “CNJ needs to adopt measures to control the efficiency of judicial expenses", Legal Consultant Magazine.

United Nations Development Program (2016), "The MDGs' sustainable development goals", available from: http://www. pnud.org.br/ODS.aspx. (Access: 20 Jun 2016).

Received: Jan 15, 2018

Approved: Jan 11, 2018

DOI: 10.14488/BJOPM.2018.v15.n1.a12

How to cite: Moreira, A. C. S. (2018), "Application of the sustainable logistics plan in the public administration", Brazilian Journal of Operations \& Production Management, Vol. 15, No. 1, pp. 137-142, available from: https:// bjopm.emnuvens.com.br/bjopm/article/view/432 (access year month day). 